Anuario Latinoamericano Ciencias Políticas y Relaciones Internacionales vol. 5, 2017

pp. 33-60

\section{El cambio en la ontología y epistemología de la ciencia de relaciones internacionales}

DOI: $10.17951 /$ al.2017.5.33

\section{The change in ontology and epistemology of the science of international relations}

\author{
Marek Pietraś* \\ FACULTAD DE CIENCIAS POLÍTICAS \\ UNIVERSIDAD MARIA CURIE-SKŁODOWSKA \\ LUBLIN, POLONIA \\ $\triangle$ pietras@poczta.umcs.lublin.pl
}

\title{
RESUMEN
}

El objetivo de este artículo es analizar la relación entre el cambio de la realidad internacional y la adecuación de la respuesta a este cambio de parte de las existentes escuelas de pensamiento sobre las relaciones internacionales. Así pues, se trata de la relación entre la ontología y la epistemología de la ciencia de las relaciones internacionales. Se ha asumido que el cambio es una característica de la realidad internacional, y la lógica de este cambio, en el actual proceso de globalización, es definida por la transición del orden internacional westfaliano hacia el orden westfaliano tardío. Sin embargo, la mayoría de las escuelas de pensamiento que desarrollaron la epistemología de la ciencia de relaciones internacionales fueron creadas bajo el orden internacional westfaliano. ¿Son capaces entonces de explicar o interpretar esta cambiada y cambiante realidad internacional? Para los objetivos que plantea este análisis, se tomaron dos supuestos. Primero, la dinámica y cambiante realidad internacional, siendo el objeto de estudio de la ciencia de relaciones internacionales, es una variable que condiciona el desarrollo del pensamiento teórico. Es decir, se ha asumido que el cambio ocurrido en la esfera ontológica condiciona la esfera epistemológica. Segundo, se ha reconocido que la ciencia de las relaciones internacionales ha entrado en un período de cambio tanto del objeto de estudio como de las herramientas científicas. Se considera que los rasgos esenciales de la realidad westfaliana tardía son el pluralismo y el carácter híbrido del ámbito subjetivo y objetivo, así como también la creciente

1 Politólogo, profesor titular, director del Departamento de Relaciones Internacionales y decano de Investigación y Cooperación Internacional en la Facultad de Ciencias Políticas de la Universidad Maria Curie-Skłodowska en Lublin, Polonia. Se dedica a la investigación en el área de la seguridad internacional, problemática ambiental en las relaciones internacionales, teoría de las relaciones internacionales, procesos de globalización y el surgimiento del llamado orden internacional westfaliano tardío. Es autor de más de 170 publicaciones científicas. 
Dossier

América Latina: desarrollo y balance de la ciencia política complejidad del entorno internacional. Por lo tanto, el propósito de este trabajo es analizar la influencia del cambio de la realidad internacional, la cual es el objeto de estudio, sobre los enfoques teóricos. En el sentido metodológico, el cambio en las relaciones internacionales es tratado como una variable independiente, mientras que el cambio en la teoría de las relaciones internacionales es considerado como una variable dependiente. En el artículo se ha verificado la hipótesis según la cual con el carácter pluralista e híbrido del entorno internacional westfaliano tardio corresponde el pluralismo y el eclecticismo de los enfoques teóricos, los cuales se han convertido en „una caja de herramientas".

PALABRAS CLAVE: ciencia de las relaciones internacionales, ontología y epistemología de las relaciones internacionales, cambio, orden internacional westfaliano y westfaliano tardío.

\section{ABSTRACT}

The purpose of this article is to analyze the relation between the change of international reality and the adequacy of the response to this change within the existing schools of thought on international relations. Hence, it is the issue of the relation between ontology and epistemology of the science of international relations. It has been assumed that the change is a characteristic feature of international reality, and the logic of this change, under the ongoing globalization processes, is defined by the transition from the Westphalian to late-Westphalian international system. However, most schools of thought which developed the epistemology of the science on international relations were created under the Westphalian international system. The question thus arises as to whether these schools of thought are able to explain and interpret this changed and changing international reality. For the purposes of the analysis, two assumptions have been made. Firstly, that the dynamic and changing international reality, being the object of the study of the science of international relations, is a variable which determines the development of the theoretical framework. In other words, it has been assumed that the change in ontology determines the change in the epistemological sphere. Secondly, it has been recognized that the science of international relations has entered a period of change of the object of study as well as of the scientific tools. It is assumed that the essential features of the late-Westphalian reality are pluralism and hybrid nature of the subject and object scope as well as the increasing complexity of the international milieu. Therefore, the aim of this work is to analyze the influence of change of international reality, which is the object of study, on the theoretical approach. From the methodological standpoint, the change of international relations is considered an independent variable, whereas the change in the theory of the international relations is a dependent variable. The author verifies the hypothesis according to which the pluralist and hybrid character of the lateWestphalian international environment is reflected in the pluralism and eclecticism of theoretical approaches, converted into a "toolbox".

KEYWORDS: science of international relations, ontology and epistemology of international relations, change, Westphalian and late-Westphalian international order. 
En el campo de la ciencia de relaciones internacionales, un problema de investigación esencial es el análisis de las relaciones entre la evolución del objeto de investigación, es decir, las cambiantes relaciones internacionales que constituyen la esfera de la realidad social, por un lado, y la explicación e interpretación de esta realidad, por el otro (Pietraś 2015a). En otros términos, se trata de la relación entre la ontología y la epistemología de esta disciplina. El objeto de investigación de la ciencia de relaciones internacionales es un proceso dinámico que experimenta un cambio constante. Tal es la especificidad de las relaciones sociales - a las que pertenecen las relaciones internacionales - las cuales son dinámicas y cambiantes por su propia naturaleza. Su contemporánea característica diferenciadora es, por un lado, -particularmente bajo el imperio de los procesos de globalización - la ampliación del ámbito objetivo, subjetivo, espacial, así como la rapidez de los cambios históricos, y por el otro lado, - la adquisición de las características nuevas, cualidades desconocidas antes. En la literatura disponible se las identifica a veces con el proceso de transición del orden internacional westfaliano hacia el orden westfaliano tardío (Pietraś, Marzęda 2008; Pietraś 2007). Sin embargo, la mayoría de las escuelas de pensamiento teórico dentro del maco de la ciencia de relaciones internacionales fueron creadas bajo el orden internacional westfaliano, con la intención de su explicación o interpretación. Por consiguiente, cabe plantearse la cuestión si las teorías establecidas en la realidad westfaliana son capaces de proporcionar explicaciones o interpretaciones de la realidad westfaliana tardía. Así pues, se trata de la cuestión si los enfoques teóricos se ajustan a la cambiada y cambiante realidad.

Con la intención de encontrar la respuesta a la pregunta antes mencionada, se ha asumido que la dinámica y cambiante realidad internacional, siendo el objeto de estudio de la ciencia de relaciones internacionales, es una variable que condiciona el desarrollo del pensamiento teórico. Es decir, se ha asumido que el cambio ocurrido en la esfera ontológica condiciona la esfera epistemológica.

Se ha reconocido que la ciencia de relaciones internacionales ha entrado en un período de cambio tanto del objeto de estudio como de las herramientas científicas. Se considera que los rasgos esenciales de la realidad westfaliana tardía son el pluralismo y el carácter híbrido del ámbito subjetivo y objetivo, así como también la creciente complejidad del entorno internacional. Por lo tanto, el propósito de este trabajo es analizar la influencia del cambio de la realidad internacional, la cual es el objeto de estudio, sobre los enfoques teóricos. En el sentido metodológico, el cambio en el ámbito de las relaciones internacionales es tratado como una variable independiente, mientras que el cambio en el área de la teoría, metodología e terminología es considerado como una variable dependiente. En el artículo, se ha verificado la hipótesis según la cual con el carácter pluralista e híbrido del entorno internacional westfaliano tardío corresponde el pluralismo y el eclecticismo de los enfoques teóricos, los cuales - en el contexto de la compleja e híbrida realidad internacional - se convierten
El cambio en la ontología y epistemología de la ciencia de relaciones internacionales

Marek Pietraś 
Dossier

América Latina:

desarrollo y balance de la ciencia política en "una caja de herramientas" (Walt 1998: 42-43) que sirven para "el procesamiento" cognitivo de complejos problemas internacionales, mientras que el papel del investigador es conocer las herramientas que están a su disposición y efectuar su selección adecuada al problema bajo investigación.

\section{La ontología de la ciencia de relaciones internacionales}

Las relaciones internacionales son una especie de relaciones sociales. Sin entrar a examinar los matices de su definición, según el ámbito subjetivo o subjetivo-objetivo, o en la categoría de las actividades sociales (Pietraś 2007a: 18-19), no hay desacuerdo en cuanto a su esencia. Ésta se compone de las actividades, interacciones y flujos transfronterizos. El ámbito transfronterizo es una condición indispensable para que existan relaciones internacionales como una especie de relaciones sociales y para que exista su ontología. Una cuestión aparte es el definir quién emprende las actividades transfronterizas y qué constituye el flujo transfronterizo. Éste es el objeto de investigación en la ciencia de relaciones internacionales; la investigación efectuada con la aplicación de un "aparato" teórico, metodológico y el marco conceptual adecuado.

Existe una opinión generalizada que la ciencia de relaciones internacionales nació a raíz de una decisión política tomada el 30 de mayo de 1919 durante la conferencia de paz al terminar la Primera Guerra Mundial. Las delegaciones de Gran Bretaña y Estados Unidos decidieron establecer en ambos países centros de investigación de relaciones internacionales. Ya en el año 1920 fue creado en Gran Bretaña el Instituto Británico de Asuntos Internacionales, renombrado en 1926 como el Instituto Real de Asuntos Internacionales, mientras que en los Estados Unidos fue fundado el Consejo de Relaciones Exteriores. Ambas instituciones fueron relacionadas con los gobiernos de sus países, respectivamente. En 1920 fue creada también la primera cátedra de relaciones internacionales, es decir, una estructura académica, en la Universidad de Gales (Meyers 1991: 221).

Tales circunstancias del nacimiento de la ciencia de relaciones internacionales fuertemente determinaron su futuro desarrollo. Primero, fue creada en el ámbito angloamericano. Segundo, nació por la necesidad de parte de la práctica política y, al mismo tiempo, fue encargada con la misión de construir un entorno internacional pacífico. Tercero, en consecuencia de lo anterior, fue la política internacional de los Estados - con un particular enfoque sobre la cuestión de la paz y la guerra - que se convirtió en el objeto de investigación. Por consiguiente, se limitó el ámbito subjetivo a los Estados mismos, y el ámbito objetivo a la interacción entre los Estados en el campo de la paz y la guerra. Así pues, en aquella época, la política internacional de los Estados, es decir, las actividades transfronterizas de los centros del poder político en un estrecho ámbito del mantenimiento de paz o la declaración de guerra, empezó a definir la esencia y la especificidad de las relaciones internacionales y así condicionar el objeto y los métodos de investigación dentro del marco de la 
ciencia de relaciones internacionales. Esta línea de pensamiento se ve reflejada en la literatura. Steve Smith escribió que las relaciones internacionales en su forma "clasica" fueron enfocadas sobre el análisis de las causas de las guerras y las condiciones de la paz (Smith 2013: 1). William Wallace, a su vez, opinó que las relaciones internacionales como una disciplina de la ciencia nacieron de la reflexión sobre la política, sobre cómo se puede ejercer influencia sobre ella y cómo cambiar la práctica política (Wallace 1996: 301). Nicholas Rengger y Joseph Thirkell-White (2007: 3) compartieron esta línea de pensamiento.

Este enfoque en el proceso investigativo sobre el Estado y sus interacciones políticas con otros Estados - es decir, un estrecho ámbito subjetivo y objetivo - tuvo lugar en el entorno internacional caracterizado por unos rasgos específicos, centrado en el rol de Estado, a veces llamado el orden westfaliano, en referencia a la simbólica fecha del tratado de paz firmado en 1648 en Westfalia. Este orden, teniendo en cuenta la lógica de su organización y funcionamiento, fue coherente, enfocado sobre el Estado nacional centralizado y sus acciones. Su creación cambió radicalmente la estructura subjetiva y, consecuentemente, la lógica del funcionamiento del entorno internacional. Las relaciones internacionales empezaron a ser percibidas como las relaciones entre las naciones organizadas en los Estados. Así pues, emergió un sistema centrado en el Estado. Esto supuso un cambio cualitativo de la organización de la vida social en comparación con la Edad Media, ya que la creación de un Estado nacional centralizado conllevó la consolidación de la ejecución de tales valores como la seguridad, el orden, la estabilidad y la justicia dentro de una estructura coherente que tenga el derecho exclusivo de regir la vida social en un territorio determinado de forma independiente de otros Estados. Esta exclusividad "hacia dentro del Estado" y la independencia "por fuera del Estado" recibió el nombre de la soberanía (Łoś-Nowak 2006: 252). Esta idea se convirtió en una regla principal de la organización y funcionamiento del sistema internacional westfaliano centrado en el Estado (Pietraś 2008: 57-58). La consecuencia de este hecho fue el limitado ámbito de los procesos de internacionalización, actividades y flujos transfronterizos así como también la clara separación entre la esfera intraestatal y la internacional.

Hay bastante unanimidad en las opiniones sobre los "parámetros" o elementos que crean un "patrón" de la organización y funcionamiento del entorno internacional denominado el sistema westfaliano. Estos elementos son los siguientes: 1) la forma de organización de las comunidades políticas fue un Estado nacional centralizado y todo el sistema internacional fue centrado en los Estados; 2) los Estados fueron estructuras territoriales y su autoridad fue limitada a una área concreta, definida con precisión por las fronteras establecidas; 3) los Estados nacionales centralizados fueron soberanos y soberanamente iguales, lo que significaba la exclusividad de su autoridad sobre su propio territorio interno y la independencia en el entorno internacional, sin someterse a cualquier otro poder superior; 4) las relaciones entre los Estados centralizados y soberanos fueron regidas por el derecho internacional,
El cambio en la ontología y epistemología de la ciencia de relaciones internacionales

Marek Pietraś 
Dossier América Latina: desarrollo y balance de la ciencia política el cual reemplazó los lazos religiosos en el papel del factor aglutinante en la comunidad internacional; 5) para la regulación del funcionamiento del entorno internacional sirvió - aparte del derecho internacional - un mecanismo de equilibrio de poder (Kuźniar 2006: 16; Valaskakis 2000; Pietraś 2008: 58-59).

El entorno internacional con las características mencionadas constituía la esfera ontológica de la ciencia de relaciones internacionales, condicionando también la esfera epistemológica. Condicionaba el enfoque sobre el Estado, sobre la política de los Estados y - sin olvidarse de la naturaleza cambiante de la vida social - sobre una realidad bastante estática y un planteamiento igualmente estático. Condicionaba el desarrollo de la teoría de relaciones internacionales, el desarrollo de los metodos de investigación y del marco conceptual. El realismo y el liberalismo, las escuelas de pensamiento teórico más significativas - en particular, el realismo - surgieron bajo el sistema internacional westfaliano y con el propósito de investigar el dicho sistema. Fueron creadas, pues, tal como muchas otras escuelas, en la realidad internacional caracterizada por ciertos "parámetros", los cuales actualmente experimentan muchos cambios. Por consiguiente, la ciencia de relaciones internacionales tiene que enfrentar un reto de ajustar su "aparato investigativo" a la realidad internacional que ha experimentado cambios en comparación con el período anterior y que constantemente se está transformando.

Un diferenciador clave del actual cambio de la realidad internacional a veces denominada como el orden westfaliano tardío - no es un cambio como tal, pero un cambio cualitativo. Sin embargo, esto no significa que el orden westfaliano está siendo reemplazado en su totalidad, o que ya ha sido reemplazado por un orden internacional con unos "parámetros" completamente nuevos. Los elementos de la realidad westfaliana funcionan al lado de una realidad nueva, desconocida antes, por eso el nombre del orden westfaliano tardío. Su rasgo distintivo es el carácter híbrido, la fusión de los sujetos, estructuras y mecanismos de funcionamiento que frecuentemente tienen características o lógica de organización totalmente opuestas. Pues, se trata de un entorno que no es homogéneo, y este hecho aún incrementa el nivel de su complejidad (Pietraś 2008). En la continuación se analizarán: 1) los factores que contribuyen al cambio del sistema westfaliano y el surgimiento del sistema westfaliano tardío, los cuales son identificados con los procesos de globalización; 2) el efecto del cambio en forma de los "parámetros" - unas características nuevas cualitativas del entorno westfaliano tardío; 3) la ampliación del ámbito objetivo de los procesos de internacionalización; 4) el cambio de la estructura subjetiva, su bifurcación y hiperpoliarquía; 5) la creciente importancia del nivel del sistema internacional; 6) el cambio de los mecanismos del manejo del entorno internacional. Estos elementos reflejan la progresiva complejidad del entorno internacional y, consecuentemente, de la esfera ontológica de la ciencia de relaciones internacionales. En este contexto, parece justificada la opinión que la lógica del cambio del entorno internacional westfaliano tardío es determinada por la regla de su creciente complejidad. 
El principal factor de cambio del sistema internacional westfaliano, de su emergente carácter híbrido y su nueva forma llamada el orden westfaliano tardío es el proceso de globalización. (Pietraś 2008: 60). Esto significa el desarrollo de los fenómenos y procesos que poseen rasgos cualitativos nuevos, diferentes de los rasgos característicos del sistema de relaciones internacionales westfaliano. El fondo de la nueva cualidad de la vida social relacionada con los procesos de globalización y la emergencia de la construcción híbrida del orden internacional westfaliano tardío se encuentra en la "compresión tiempoespacio" (Kempny 2000: 9). Esta idea es generalmente compartida en la literatura científica sobre los procesos de globalización. Anthony Giddens sugirió inclusivamente la introducción de la cuarta dimensión del espacio social en forma de condicionamientos globales que son relativamente desprovistos del lugar, distancias y fronteras (citado por Schachter 1999: 79).

La compresión del tiempo y del espacio se manifiesta en varias maneras que reflejan los cambios cualitativos del entorno internacional y contribuyen a su hibridación. Primero, aparece el fenómeno de la desterritorialización (de-territorialization) de algunos fenómenos y procesos sociales. Aquellos ocurren, según este mecanismo, sin una localización definida en el espacio determinado del globo. Además, las distancias no tienen ninguna importancia para su funcionamiento. Esto significa un claro desviamiento de la regla de territorialidad característica para el sistema de relaciones internacionales westfaliano. De acuerdo con esta regla, los fenómenos y procesos "pertenecen" a un cierto territorio. Mientras tanto, los procesos de globalización inician las interacciones y conexiones sin tener en cuenta distancias, no "a través" de un territorio, sino en una relativa independencia de una localización concreta (Scholte 1996: 49). Esto se refiere, en particular, a los flujos de finanzas, capital, información, así como también los problemas ecológicos transfronterizos y globales, por ejemplo, los relacionados con la reducción de la capa de ozono o con los cambios climáticos. Esto significa una mayor permeabilidad de las fronteras estatales y el desvanecimiento de la separación entre lo intraestatal y lo internacional, tan característica para el orden westfaliano (Pietraś 2002a: 5-34; Pietraś 2002b: 35-66). El mecanismo de la "desterritorialización" incrementa sustancialmente la hibridación de las relaciones internacionales. Las "tradicionales", westfalianas, siendo relaciones de interterritoriales, es decir, las interacciones que cruzan las fronteras a través de la distancia geográfica, existen al lado de las interacciones y conexiones "desterritorializadas", desarrolladas independientemente de las distancias territoriales. Se formula, inclusive, la idea que las concepciones de lugar, distancia y fronteras no son adecuadas para la descripción del "desterritorializado" ciberespacio, el calentamiento global o los flujos del capital o información (Scholte 1996: 16).

La "compresión" del espacio y el mecanismo de la "desterritorialización" de los fenómenos y procesos del la vida social bajo la globalización no significan, sin embargo, que el factor territorial deje de ser relevante. Esto se ve confirmado en el hecho de que existe la demanda para el territorio en la si-
El cambio en la ontología y epistemología de la ciencia de relaciones internacionales

Marek Pietraś 
Dossier América Latina: desarrollo y balance de la ciencia política tuación del creciente número de población, conflictos étnicos relacionados con el territorio, la producción de alimentos, la cual, por lo general, necesita un territorio y un espacio, etc. (Rosenau 1999: XIV). Así pues, los procesos de globalización no eliminan por completo la importancia de la distancia y de las fronteras territoriales en las relaciones internacionales. No obstante, introducen un espacio adicional, supraterritorial, por ejemplo, en la forma del ciberespacio (Scholte 1997: 18). Esto significa una cierta bifurcación, hibridación $y$, en efecto, la coexistencia del espacio tradicional, definido territorialmente, y el espacio modificado por los procesos de globalización, relativamente desprovisto del lugar, distancias y fronteras, transformando el mundo en un lugar condensado, único. En tales circunstancias, las escuelas de pensamiento teórico establecidas bajo las condiciones del sistema de relaciones internacionales westfaliano no dejan de ser útiles. Sin embargo, no son suficientes para la explicación o interpretación de la creciente complejidad del sistema westfaliano tardío. En consecuencia, se convierten en las teorías parciales.

Segundo, existe el fenómeno del espacio social transnacional, de acuerdo con el cual se mantienen intensas interacciones y conexiones entre grupos sociales independientemente de las distancias territoriales y, además, fuera o con un limitado control de parte de los Estados nacionales. Este mecanismo también significa una desviación del orden internacional westfaliano, ya que los fenómenos y procesos no solamente salen de los límites impuestos por las fronteras estatales, sino también "se escapan" del control de sus gobiernos como estructuras de manejo. Es más, bajo las condiciones de la mayor permeabilidad de las fronteras y la progresiva intensificación de los fenómenos transnacionales característicos para los procesos de globalización, el entorno internacional, por decirlo así, "se derrama" dentro de los Estados, influyendo su funcionamiento. La información, el capital, los valores culturales, las amenazas ecológicas, las organizaciones terroristas, las estructuras del crimen organizado, etc., penetran las fronteras como si ellas no existieran. Por consiguiente, es necesario redefinir el principio de la soberanía entendido en términos tradicionales, es decir, como un "fundamento" del sistema de relaciones internacionales westfaliano. Una parte de la vida social - ateniéndose a la terminología de J. N. Rosenau - es transferida al espacio post-soberano (post-sovereign space) (Rosenau 1996: 251). Otra parte sigue en el espacio soberano, rodeado por las fronteras estatales cada vez más porosas.

Tercero, en lo que se refiere a los procesos de globalización, el mundo se convierte en un lugar único (single place). De acuerdo con este mecanismo, uno "siente" el mundo independientemente de las distancias espaciales, ya que estamos a la vez "tanto aquí como ahí". Esta metáfora muestra claramente el cambio de la lógica espacial de la organización de la vida social bajo los procesos de globalización. En el "clásico" entorno internacional westfaliano, este espacio fue limitado por las fronteras de los Estados. Los procesos de globalización suprimen estas limitaciones. Mientras que en el mundo "territorial" del orden westfaliano las distancias entre los Estados condicionaban la posi- 
bilidad e intensidad de contactos entre los Estados y las sociedades, bajo la globalización surgen fenómenos y procesos que, por lo menos parcialmente, son independientes del espacio definido territorialmente (Scholte 1999: 1112), cerrado por las fronteras de los Estados. Esto significa también que la ubicación geográfica de los Estados y las fronteras entre ellos son cada vez menos importantes en la vida social.

Los procesos de globalización, como un factor cualitativo de los cambios, determinan el surgimiento del entorno internacional westfaliano tardío, dependen de numerosas variables. Para explicarlas a fondo es necesario tomar en cuenta el efecto de sinergía de las fuerzas interconectadas del campo político, económico, tecnológico, ecológico, psicológico y otros. En particular, los factores tecnológico y político requieren una atención especial ya que para la aparición de una nueva calidad de la vida social, diferente de las reglas del entorno internacional westfaliano, contribuyó una fusión excepcional en la historia humana entre el desarrollo tecnológico que alcanzó niveles extraordinarios, y el dominante orden político que permitió que ocurran estos cambios generados por el factor tecnológico.

El factor tecnológico es el que causa que de los procesos de globalización caracterizados por la "compresión" del tiempo y espacio - sean procesos objetivos y, según parece, irreversibles, independientes de las decisiones y acciones de los líderes de diferentes países y las élites políticas relacionadas con ellos. Esto significa que la forma híbrida de la estructura subjetiva y de los mecanismos de funcionamiento del entorno internacional - aunque en la perspectiva temporal difícil de prever - será reemplazada por las soluciones propias al orden post-westfaliano.

En la historia de la humanidad, el desarrollo de la técnica y la tecnología se ha ido acumulando y reforzando, de hecho, la importancia del factor tecnológico. Adicionalmente, durante las últimas décadas, el mundo ha estado atravesando por un período de una enorme innovación tecnológica, relacionada con la emergencia del tecnocapitalismo y la subsiguiente aceleración histórica, sin precedentes en la historia anterior. En consecuencia, han ocurrido cambios en la organización y funcionamiento de la vida social en forma de la reorganización de la economía mundial, la evolución de procesos políticos, los nuevos desafíos relacionados con la identidad nacional, los nuevos medios de comunicación y transporte, etc. (Kellner 1998), los cuales socavan los principios fundamentales del sistema internacional westfaliano, tales como, por ejemplo, la territorialidad y la soberanía.

Según la opinión de J. N. Rosenau, televisión vía satélite, acceso a internet, cables de fibra óptica, etc., han reducido las distancias a milisegundos. Por estos medios, las palabras, ideas, imágenes e informaciones llegan inmediatamente a millares de personas. Los cambios de la organización y funcionamiento de la vida social ocurren con una velocidad acelerada, estimulando las cuatro "revoluciones" paralelas e interconectadas. Primero, la así llamada revolución de las capacidades de la gente "común", sus conocimientos y cua-
El cambio en la ontología y epistemología de la ciencia de relaciones internacionales

Marek Pietraś 
Dossier

América Latina:

desarrollo y balance de la ciencia política lificaciones profesionales, lo que, en resultado, les permite incrementar su rol como sujetos de la vida social, inclusive en el plano de las relaciones internacionales. El poder de la gente común es un elemento esencial en el cambio de las relaciones internacionales contemporáneas. Segundo, la llamada explosión de las habilidades organizativas bajo la revolución de capacidades. Sube de forma vertiginosa el número de las organizaciones transnacionales de sociedad civil, de los defensores de derechos humanos o de medioambiente, etc., los cuales pueden ahora aprovechar unas nuevas formas de organizarse y llevar sus actividades, utilizando, por ejemplo, la comunicación por internet. Tercero, la revolución en cuanto a la movilidad, es decir, la posibilidad de moverse y mantener contactos, así como emprender acciones en las áreas alejadas del lugar de procedencia. Cuarto, el cambio de las estructuras de organización y manejo de la vida social. Al lado de las tradicionales estructuras jerárquicas, gracias a los nuevos medios de transporte y comunicación, se desarrollan unas nuevas estructuras de redes horizontales (Rosenau 2006: 6-7). Estas redes son capaces de movilizar la actividad de cientos de organizaciones cívicas de varios países. El papel del factor tecnológico percibido de esta perspectiva relativiza la importancia del factor político y, al mismo tiempo, muestra que los procesos de globalización son irreversibles.

Teniendo en cuenta las mencionadas nuevas características cualitativas del entorno internacional bajo los procesos de globalización, hay que indicar unos cuantos cambios más que diferencian el orden westfaliano y el orden westfaliano tardío. Estos cambios llevan, por un lado, a la desaparición de la "nitidez" de la división entre lo intraestatal y lo internacional, tan característica al orden westfaliano. Por otro lado, llevan a una singular "despolitización" de las relaciones internacionales, tomando más en consideración otros planos, tales como económico, cultural, ecológico, social, científico, etc.

Primero, el siguiente cambio relevante para el funcionamiento del entorno internacional westfaliano tardío es la ampliación y profundización de los procesos de internacionalización. Estos procesos constituyen una de las condiciones de la transfronterización de las relaciones internacionales y suponen un cambio de lo intraestatal en un elemento de funcionamiento del entorno internacional. En este aspecto, una tendencia clara es la ampliación del ámbito objetivo de estas relaciones, ya que se refieren al comercio, movimientos de capitales, flujo de mano de obra, circulación de ideas, valores y cultura, flujo de información, amenazas de seguridad como el terrorismo o el crimen organizado transnacional, problemas ecológicos, etc. (Kukułka 1991). Así pues, los procesos de internacionalización tocan cada vez más amplio ámbito de la vida social, y se caracterizan por la creciente intensidad dentro de cada ámbito mencionado. Además, son afectados por la globalización y el funcionamiento a escala global. Su resultado importante es el crecimiento de las interdependencias internacionales, es decir, tal estado de relaciones entre sociedades y Estados que los cambios ocurridos en unos afectan a los otros (Kuźniar 1988). A su vez, esto corrobora la "superposición" y permeabilidad entre lo 
intraestatal y lo internacional, tan característica al orden westfaliano tardío, así como la ampliación del ámbito objetivo de las relaciones internacionales por otros planos, aparte del plano político, dominante anteriormente. Se nota una creciente importancia de los problemas sociales y económicos. Al ser sometidos a la internacionalización, se convierten en el objeto de regulaciones dentro del marco de las decisiones políticas, y esto significa que el ámbito objetivo de las relaciones internacionales sobrepasa las cuestiones de la paz y la guerra, propias al orden westfaliano.

Segundo, un proceso importante que contribuye al desvanecimiento de la separación entre el Estado y el entorno internacional, e inclusive causa la "superposición" y dependencia mutua de estos campos, es el desarrollo del mencionado ya transnacional espacio social, es decir, la actividad transfronteriza de los sujetos no estatales. Su actividad lleva al alejamiento de la westfaliana estructura subjetiva de relaciones internacionales centrada en el Estado. En este contexto, ya al final de los años 80 del siglo XX, James Rosenau escribió sobre la bifurcación subjetiva de la estructura del entorno internacional, es decir, la partición al "mundo de Estados" y el "mundo multicéntrico" compuesto por los sujetos transnacionales (Rosenau 1989: 8; Rosenau 1990; Rosenau 1988: 327-364).

Generalmente, a los sujetos transnacionales de las relaciones políticas internacionales se incluyen las corporaciones transnacionales, las organizaciones no gubernamentales (NGOs) que empoderan a los representantes de la sociedad civil como sujetos de las relaciones internacionales, los movimientos liberadores, las organizaciones terroristas, las estructuras del crimen organizado, las organizaciones religiosas, los movimientos políticos internacionales, es decir, las secciones internacionales de los partidos políticos (Pietraś, Piórko 2007: 142). También se incluyen diferentes tipos de fundaciones filantrópicas, las redes territoriales transnacionales y las así llamadas comunidades epistémicas. Su número así como también su diversidad tienen un fuerte impacto sobre la estructura subjetiva del entorno internacional, profundizando su poliarquía. De este modo, el entorno internacional se hace hiperpoliárquico (Pietraś 2015: 51-68). Su descentralización es el resultado no sólo de la existencia de aproximadamente 200 Estados centralizados, pero también de los cientos de miles de sujetos transnacionales.

Los enumerados cambios cualitativos que tienen lugar en el entrono internacional llevan al incremento de la importancia en el orden westfaliano tardío de los cambios que ocurren en el nivel internacional. Esto es un cambio significativo en comparación con el orden westfalinano, en el cual dominaban las actividades emprendidas por unos países hacia otros países en lo que se refería a la paz o la guerra. Las investigaciones llevadas a cabo en el campo de la ciencia de relaciones internacionales - si efectuaban el análisis al nivel internacional - se enfocaban en los elementos estructurales, por ejemplo, la poliarquía o la polaridad del entorno internacional centrado en los Estados. La primera línea de pensamiento, la representaba Kenneth Waltz (Waltz 1979),
El cambio en la ontología y epistemología de la ciencia de relaciones internacionales

Marek Pietraś 
Dossier América Latina: desarrollo y balance de la ciencia política mientras que la segunda, Morton Kaplan (Kaplan 1964), entre otros, y, en lo que se refiere a la literatura polaca, Andrzej Gałganek (Gałganek 1992).

Sin negar la importancia de los mencionados antes condicionamientos estructurales de funcionamiento del sistema internacional y su utilidad para el análisis de las relaciones internacionales contemporáneas, hay que enfatizar que en el sistema westfaliano tardío aumenta la importancia de los condicionamientos procesuales, relacionados con los cambios cualitativos. Por lo tanto, crece la importancia de los procesos de globalización al nivel internacional, la actividad de los sujetos transnacionales, los flujos transfronterizos del capital y de la mano de obra, los procesos migratorios, los problemas ecológicos, por ejemplo, los cambios climáticos, o las amenazas terroristas (Pietraś 2009: 17-45).

La lógica de la argumentación a favor de los cambios cualitativos que condicionan el sistema internacional y de la preeminencia de los cambios "procesuales" sobre los “estructurales", la logró captar aptamente Oliver Richmond (Richmond 2002: 35). Según su opinión, después del fin de la guerra fría, en el entorno internacional enfrentamos el cambio de la lógica de las fuerzas que funcionan a nivel del sistema internacional. Durante la guerra fría dominaban las fuerzas relacionadas con el funcionamiento del Estado, su potencial, y, por consiguiente, existía la polaridad del entorno internacional. Así pues, dominaban los condicionamientos "estructurales". Mientras que, al terminar la guerra fría y en consecuencia de los crecientes procesos de globalización, el funcionamiento del Estado es condicionado por los procesos que ocurren a nivel del entorno internacional, a escala global o regional y los procesos a nivel local, relacionados con la actividad, ante todo, de los sujetos transnacionales. Entonces, dominan los condicionamientos de carácter "procesual” (Pietraś 2009: 21).

El enfoque sobre los cambios cualitativos a nivel del sistema internacional no significa que se pasa por alto el Estado como una forma principal de organización de la vida social y el sujeto de la política y del poder político, la importancia de la política exterior (Łoś-Nowak 2011) y, por lo tanto, el plano político de las relaciones internacionales. No obstante, hay que subrayar que los cambios cualitativos del entorno internacional identificados con el orden westfaliano tardío crean un nuevo entorno para el funcionamiento de los Estados, forzando los procesos de adaptación. Se cambia el proceso de toma de decisiones en la política exterior del Estado (Pugacewicz 2014), pero también la organización y el funcionamiento de la diplomacia (Surmacz 2015). El problema de la inefectividad de estructuras de ejercer el poder en varios Estados, el cambio de sus funciones en disfunciones, el cual se define como un Estado fallido, se convierte en una cuestion importante para investigar (Gil 2015; Kłosowicz, Mania 2012).

En la realidad internacional que pasa por unos cambios radicales, un problema importante - también en el campo investigativo - es la cuestión de gobernanza de esta realidad. El rasgo característico de este proceso es la hibridación de estructuras y mecanismos que unen los formados bajo el orden westfaliano con los surgidos en el orden westfaliano tardío. Los mecanismos 
y estructuras formados bajo el orden internacional westfaliano fueron relacionados principalmente con la dominación hegemónica, y a la vez imperial, de los poderes mundiales, el mecanismo de balance del poder y, más tarde, también el desarrollo de las instituciones en forma de las organizaciones intergubernamentales y las regulaciones legales internacionales. Sin embargo, no hay que olvidar que los procesos de globalización que condicionan el surgimiento del orden westfaliano tardío no eliminan totalmente los mencionados mecanismos y estructuras de gobernanza característicos para el orden westfaliano, sino añaden los nuevos a los ya existentes. Pues, tenemos elementos de continuidad y cambio y, además, la hibridación de las soluciones actuales (Pietraś 2008).

En el contexto de la continua existencia y funcionamiento de las estructuras y los mecanismos de gobernanza "westfalianos" en forma de la hegemonía de los poderes mundiales, el mecanismo de equilibrio de poder, el derecho internacional y las instituciones internacionales, inclusive los regímenes internacionales (Pietraś 2014: 15-71), se están formando los "westfalianos tardíos". Su "contraseña" es la idea de la gobernanza global (global governance) (Marzęda-Młynarska 2014; Zachara 2012). Esta idea es el resultado - como lo indican Tanja Brühl y Volker Rittberger - de una red sin jerarquía de las instituciones intergubernamentales y transnacionales. Lo que diferencia este tipo de gobernanza del que fue característico para el entorno internacional westfaliano es cada vez más amplia participación de los sujetos no estatales, lo que en resultado crea una estructura híbrida. Además, esta gobernanza, en el contexto de la permeabilidad entre lo intraestatal y lo internacional, tan característica bajo los procesos de globalización, se convierte en una estructura de gobernanza de niveles múltiples. Se efectua no solo a nivel de los gobiernos, pero también a nivel local, regional y global (Bruehl, Rittberger 2001: 2). Un elemento complementario - que también existe de forma autónoma - de las estructuras de la gobernanza global son las redes creadas por las organizaciones de la sociedad civil (Panas 2013).

$\mathrm{Al}$ identificar los cambios cualitativos - los que se convierten en el objeto de investigación - de las relaciones internacionales definidas como el orden westfaliano tardío, hay que notar que en el entorno académico está creciendo la conciencia de los efectos de estos cambios para las investigaciones llevadas a cabo y las deficiencias de estos trabajos investigativos. Anthony Giddens (Giddens 1999) y David Held (Held 2004) advirtieron desde la perspectiva sociológica y politológica, respectivamente, que en el contexto de los procesos de globalización - los cuales son el principal factor del cambio y de la emergencia del orden westfaliano tardío - la ciencia de relaciones internacionales fue demasiado enfocada en el Estado como un sujeto de la política y una forma de organización de la vida social, y por eso ha tenido y sigue teniendo ciertas limitaciones para comprender el cambio por el que están pasando las relaciones internacionales contemporáneas. Esto ocurre así porque actualmente - como lo indica Ronen Palan - las relaciones internacionales no se limitan a las re-
El cambio en la ontología y epistemología de la ciencia de relaciones internacionales

Marek Pietraś 
Dossier América Latina: desarrollo y balance de la ciencia política laciones de la guerra y la paz. Se han convertido en una “... gigantesca correa de transmisión para esparcir ideas, comportamientos, normas, instituciones" (Palan 2007: 47).

Ya al principio de los años 80 del siglo XX, R. J. Vincent señaló que en la ciencia de relaciones internacionales durante mucho tiempo el problema del cambio como el objeto de investigación había sido dejado desatendido (Vincent 1983: 63). En el mismo tiempo, Robert Gilpin - aparentemente intentando explicar esta cuestión - notó que en los procesos investigativos de las disciplinas jóvenes lo estático tiene prioridad sobre lo dinámico (Gilpin 1981: 4). Esta línea de pensamiento la compartieron Barry Buzan y Barry Jones. En su opinión, las existentes aproximaciones teóricas se enfocan sobre la continuidad a expensas del cambio (Buzan, Jones 1991: 2). Mientras tanto - como, años más tarde, lo indica Ole Waever - los procesos de globalización "derrumbaron" el concepto de lo que se consideraba como lo intraestatal y lo internacional. La nueva realidad es un desafío para la disciplina y no el anuncio de su fin. Igual que la fragmentación del campo de investigación (Waever 2013: 311). Ya citado Ronen Palan considera que la ciencia de relaciones internacionales como una disciplina atraviesa por un proceso de bifurcación en dos tendencias: ortodoxa y crítica. El hecho de que existan varias escuelas de pensamiento, aproximaciones teóricas o debates metodológicos es una prueba de que la disciplina se encuentra en un proceso de cambio. (Palan 2007: 48-49). Este cambio es condicionado por el cambio de la realidad internacional. Se está formando su nueva - como lo denominó Felix Grenier - "identidad híbrida" (Grenier 2015: 250).

\section{La epistemología de la ciencia de relaciones internacionales}

El análisis de la esfera epistemológica requiere un enfoque sobre las teorías de relaciones internacionales, con una particular atención a su evolución y el potencial para la explicación, interpretación y comprensión de la cambiante realidad internacional westfaliana tardía. Las teorías son tratadas como un elemento integral e indispensable de la disciplina científica - en este caso, de la ciencia de relaciones internacionales. Hay un acuerdo generalizado que la teoría - la cual tiene sus orígenes en el griego concepto de theoria (Hudzik 2011: 111) - es una especie de transformar una realidad compleja en una forma abstracta para proveer generalizaciones sobre el objeto de investigación (Dunne, Hansen, Wight 2013: 407), convirtiéndose en una herramienta investigativa indispensable que permite descubrir relaciones entre los fenómenos supuestamente distantes (Krauz-Mozer 2011: 42). Esto resalta la importancia de la cuestión de relación entre la teoría como una abstracción y la realidad internacional dinámica y cambiante. ¿En qué medida el cambio de la realidad se refleja en la abstracción? Esta pregunta es aún más relevante, ya que la 
ciencia de relaciones internacionales actual está sometida a una presión por causa del cambio no solo del objeto de investigación, el cual se transforma y "se extiende" en el ámbito de lo transfronterizo, abarcando unos fenómenos de rasgos cualitativos nuevos, pero también porque se necesita ajustar el "aparato" teórico y metodológico a los cambios actuales para superar el enfoque anterior, también teórico, sobre la política internacional. No obstante, el reconocimiento de la necesidad de la adaptación, la cual supone un cambio de los fundamentos teóricos y su adecuación a la realidad westfaliana tardía, lleva a hacerse preguntas sobre el posible fin de la teoría internacional (KrauzMozer 2011), o un período transitorio en su adaptación a la cambiante realidad, (Silverste 2013: 610) tanto más que se le confiere a la teoría una función de herramienta que posibilita la identificación de lo esencial en las relaciones internacionales (Dunne, Hanse, Wight 2013: 410). Una condición indispensable para que la teoría cumpla esta función es su adaptación al cambio de la realidad.

Independientemente del tipo de teorías, sean las explicativas o normativas, hay un acuerdo en cuanto a la naturaleza de teorías en las investigaciones politológicas. Se la entiende como una reflexión sistematizada sobre los fenómenos que la teoría debe explicar, y mostrar como estos fenómenos están interconectados, haciéndolo de una forma lógica y ordenada. (Doughert, Pfaltzgraff 1997: 15).

Un rasgo característico del desarrollo de la ciencia de relaciones internacionales es el pluralismo teórico. Aun en el comienzo de los años 80 del siglo XX, Kenneth Waltz escribió que existe una proliferación de teorías (Waltz 1981). A su vez, Stephen Walt, al final del siglo XX, en un artículo con un título muy elocuente International Relations: One world, many theories, señalando la limitación del pluralismo teórico por causa de la dominación del realismo y su aplicación como una herramienta de investigación más útil, indicó que las teorías existentes cumplen el papel de la mencionada ya "caja de herramientas" (Walt 1998: 42-43). Crean un pluralismo intelectual en la ciencia de relaciones internacionales, el cual permite seleccionar una teoría en función del objeto de investigación, resultados esperados u otras preferencias (Smith 2013: 4).

Un rasgo característico del actual etapa de desarrollo de la teoría es la profundización del pluralismo teórico a causa de los intentos emprendidos para explicar los cambios cualitativos del entorno internacional, tomando en cuenta los condicionamientos sociales que tienen impacto sobre el entorno internacional (Dunne, Hansen, Wight 2013: 405). Esta situación es evaluada positivamente. Se señala que hay necesidad de la apertura hacia las propuestas teóricas porque solo el pluralismo teórico posibilita explicar una realidad internacional cada vez más compleja. Sin embargo, se formula también una pregunta sobre las posibles consecuencias del pluralismo teórico para la coherencia teórica de la disciplina y sobre los potenciales límites de este fenómeno. Se ha planteado incluso la pregunta sobre la posible adopción de estrategia de "brotar miles de flores teóricas" (Dunne, Hansen, Wight 2013: 416).
El cambio en la ontología y epistemología de la ciencia de relaciones internacionales

Marek Pietraś 
Dossier

América Latina: desarrollo y balance de la ciencia política
Tim Dunne, Lene Hansen y Colin Wight buscan, no sin razón, las causas del pluralismo teórico y la fragmentación teórica de la ciencia de relaciones internacionales en los factores estructurales de las relaciones internacionales, es decir, en su fragmentación y, por consiguiente, en la fragmentación de los campos de investigación. Dicho de otro modo, la fragmentación de la realidad internacional como un objeto de investigación, o sea, la esfera ontológica, conlleva la fragmentación del proceso investigativo, el pluralismo de las teorías parciales y, así pues, la fragmentación de la esfera epistemológica. Primero, subrayan que el sistema internacional atraviesa un cambio y, siendo abierto a unos nuevos fenómenos y procesos, se hace cada vez más complejo, creando una complejidad organizada (organized complexity). Segundo, las relaciones internacionales abarcan casi todos los ámbitos de la actividad social (Dunne, Hansen, Wight 2013: 417), el político, económico, cultural, energético, ecológico, deportivo, relacionado con los derechos humanos, etc., y cada uno de estos ámbitos, por un lado, atraviesa y condiciona los otros, haciendo la vida social a nivel internacional más y más interdependiente. Por otro lado, cada de los ámbitos enumerados, a pesar de la creciente interdependencia, experimenta una autonomización, cobra rasgos singulares en cuanto a los problemas para solucionar e investigar, está sometido bajo las normas regulativas y soluciones institucionales, etc. Tenemos, pues, una paradoja singular de la creciente complejidad e interdependencia de la vida social y una paralela autonomización de sus diferentes ámbitos. El pluralismo de problemas y su individualización en el marco de la creciente complejidad de la realidad internacional crea la necesidad de la „individualización” - por supuesto, dentro de la disciplina del proceso investigativo, los métodos aplicados y las aproximaciones teóricas. La fragmentación de la realidad social, o sea, la esfera ontológica, condiciona la fragmentación del proceso investigativo, o sea, la esfera epistemológica.

Los autores mencionados llegaron a la conclusión que la aparición de "miles de flores teóricas" puede volverse un problema para el desarrollo de la disciplina, ya que puede causar la relativización de las existentes aproximaciones teóricas. Para evitar tal situación, propusieron dirigirse hacia una solución llamada el pluralismo integrador. Esto significaría una aceptación y protección de un amplio espectro de planteamientos teóricos, considerándolos como una especie de valor que posibilita acercarse a la compleja realidad de una forma más polifacética, sin subordinar varias teorías a una dominante. Sugieren que los métodos investigativos pueden ser el factor que asegure la coherencia de la disciplina. Los métodos crean unas herramientas analíticas para explorar la realidad, solucionar disputas teóricas y, a la vez, integrar la disciplina. Formulan incluso la opinión que la unanimidad de los métodos puede llevar a una convergencia teórica dentro del marco de la ciencia de relaciones internacionales. Hacen referencia a las opiniones expresadas ya al final del siglo XIX, que la coherencia de la ciencia se manifiesta en su método. Así pues, el pluralismo teórico de la ciencia de relaciones internacionales puede ser aceptado dentro del marco de su coherencia metodológica (Dunne, Hansen, Wight 2013: 415-417). 
Un elemento importante - independientemente de la diversidad de opiniones - del desarrollo de la esfera epistemológica de la ciencia de relaciones internacionales y del existente pluralismo teórico son los grandes debates llamados debates interparadigmáticos, entre los “-ismos", como el idealismo, realismo, neorealismo, estructuralismo, constructivismo, feminismo. A veces son llamados como un "núcleo intelectual" (Waever 2013: 306). Destacando su importancia, David Lake indicó que estos debates se convirtieron en algunos casos en un enfrentamiento acerca de la verdad y la identificación con un paradigma concreto fue para algunos investigadores como un credo (Lake 2013: 580). Aún se discute sobre el número de estos debates, pero la mayoría de los investigadores de relaciones internacionales no se opone en aceptar el número de cuatro debates, ya que se trata de los que tuvieron un impacto significativo en el desarrollo de la disciplina (Waever 1996: 149-185; Kurki, Wight 2013: 16). Hay que recordar que la mayor parte de estos debates - si no todos - fueron llevados a cabo bajo el orden internacional wesfaliano. Sin embargo, con la siguiente "generación" de los debates interparadigmáticos, se amplía el ámbito de los fenómenos característicos para el orden westfaliano tardío tomados en cuenta en los debates y también aparecen nuevas líneas de pensamiento para su explicación, interpretación y comprensión.

El primer debate se realizó entre los idealistas y los realistas y se inició al final de los años 30 del siglo XX. Independientemente de las considerables diferencias entre ambas escuelas de pensamiento teórico, el debate fue enfocado, ante todo, en la explicación de la política internacional característica para el orden westfaliano, es decir, las relaciones entre los Estados. Tal como lo señaló Stefano Guzzini, el debate introdujo una importante dicotomía en la interpretación de las relaciones internacionales, o más precisamente, la política internacional, por los prácticos. Se hizo una clara división entre la esfera de la diplomacia y la esfera de relaciones militares así como entre la esfera de derecho internacional y la experiencia histórica (Guzzini 2013: 523). Los idealistas se basaron en el derecho internacional y representaron la confianza en las instituciones internacionales, valores y normas legales. Los realistas prefirieron el enfoque sobre el Estado, sus intereses definidos en las categorías del poder y el mecanismo de equilibrio de poder como un modo de organizar el entorno internacional. No hay que olvidar que ambas escuelas de pensamiento, formadas bajo el orden westfaliano, han ejercido y hasta hoy ejercen - en particular, el realismo - influencia sobre el desarrollo de la ciencia de relaciones internacionales y la investigación de la realidad internacional. Cuando se formaban, aspiraban a crear unas teorías completas para la explicación de las relaciones internacionales. En actualidad, bajo el orden westfaliano tardío, pueden ser solamente unas teorías parciales que explican seleccionadas acciones, fenómenos, etc., de la realidad internacional cada vez más compleja.

El segundo debate llegó a su punto culminante en los años 60 del siglo XX. El debate se llevó a cabo entre los tradicionalistas, es decir, los realistas y los idealistas, por un lado, y los behavioristas, por el otro. El tema princi-
El cambio en la ontología y epistemología de la ciencia de relaciones internacionales

Marek Pietraś 
Dossier América Latina: desarrollo y balance de la ciencia política pal se refería a los métodos de investigación. Los partidarios de la revolución behavioral mantenían que la ciencia de relaciones internacionales se podía desarrollar solo si en el proceso investigativo se aplicaba los modelos utilizados en las ciencias naturales. En la esfera de la filosofía de ciencia, la línea de pensamiento sobre el proceso investigativo fue por entonces dominada por el positivismo. Sus partidarios creían que el conocimiento científico era solamente el resultado de la colección de datos observables. Se creía que si se recogía una cantidad suficiente de datos, se podía formular unas conclusiones sobre los padrones de comportamiento, principalmente de los Estados, para buscar unas regularidades de funcionamiento y evolución de las relaciones internacionales. La base del conocimiento lo constituía la medición de los fenómenos y su cuantificación (Kurki, Wight 2013: 18).

Evaluando el segundo debate, hay que recalcar claramente que el cambio de métodos de investigación no cambió el objeto de investigación. Por lo tanto, el objeto de investigación fue el orden internacional westfaliano. Además, el método de observación, cuantificación y concentración sobre fenómenos singulares no parece ser idóneo para el análisis de lo que podía crear unos fenómenos de características cualitativas nuevas, las cuales al surgir, tenían una intensidad "ínfima".

El tercer debate interparadigmático en la ciencia de relaciones internacionales fue llevado a cabo en los años 70 y el comienzo de los años 80 del siglo XX. Mientras que en el primer y el segundo debate la "línea de combate intelectual" y las "partes del conflicto" fueron marcadas y definidas bastante unívocamente, esto ya parece más difícil, aunque no imposible, en el caso del tercer debate a causa del creciente pluralismo teórico en la ciencia de relaciones internacionales. Se pueden distinguir tres - al parecer dominantes entonces - escuelas de pensamiento: el neorealismo, el estructuralismo, llamado también el neomarxismo, y el pluralismo (Kurki, Wight 2013: 16; Pastusiak 1986: 136). No obstante, estas escuelas no fueron las únicas.

Los participantes de este debate se alejaron del tema de la metodología $\mathrm{y}$ consideraron los problemas de funcionamiento del entorno internacional como el objeto de investigación. El neorealismo se enfocaba en los condicionamientos estructurales de las relaciones internacionales que funcionan a nivel del sistema internacional, el pluralismo exponía la diversidad de los sujetos de relaciones internacionales y el estructuralismo exponía, generalmente, las desproporciones en el nivel de desarrollo y sus razones. El pensamiento "de parte" del sistema internacional, sobre la actividad de los sujetos no estatales o sobre las causas de desproporciones en el nivel de desarrollo significaba el alejamiento del pensamiento sobre las relaciones internacionales en términos de la política internacional, es decir, enfocándose en el Estado y sus acciones. Esto significó que se tomaba en cuenta unos fenómenos o modos de pensar importantes para los futuros cambios cualitativos de relaciones internacionales.

El cuarto debate empezó en la mitad de los años 80 del siglo XX. Según Davida Lake, puede ser percibido como una profundización de fragmenta- 
ción del campo de investigación entre varios grupos de pensamiento teórico, superpuestos, con su propia identidad, con el anhelo de aceptar su propia línea de pensamiento, siendo paralelamente en oposición a otros grupos (Lake 2013: 570). Esto nuevamente profundizaba el pluralismo de escuelas de pensamiento teórico y, a la vez, hacía más difícil la identificación de divisiones en el debate teórico. Milja Kurki y Colin Wight sugirieron que este debate fue/es entre: 1) la explicación y comprensión de las relaciones internacionales; 2) el positivismo y el postpositivismo; 3) el racionalismo y el reflectivismo (Kurki, Wight 2013: 19-22). El principal objeto de debate fue/es, ante todo, la disputa referente a lo qué constituye una ciencia, un conocimiento científico, y cómo investigar las relaciones internacionales, y no tanto cómo son y cómo cambian las relaciones internacionales.

La diferenciación entre la explicación y la comprensión - inspirándose en las obras de Max Weber - en la ciencia de relaciones internacionales la propagaron, al principio de los años 90 del siglo XX, Martin Hollis y Steve Smith (Hollis, Smith 1990), mientras que en las investigaciones politológicas en Polonia la emprendió Teresa Łoś-Nowak (Łoś-Nowak 2009). Los teóricos "explicativos" - inspirados por el positivismo - tienden a imitar las ciencias naturales en la esfera metodológica de la búsqueda de las razones y regularidades generales. Mientras tanto, los partidarios de la comprensión se enfocan en el análisis de lengua, razones, convicciones, significado conferido por los sujetos de la vida social. Para los partidarios de esta línea de pensamiento estos elementos son los más importantes en la esfera ontológica de la vida social. A su vez, los teóricos "explicativos" - sin negar la importancia de estos elementos - reducen la esfera ontológica a lo que se puede observar y medir. Esta aproximación diferente a la esfera ontológica lleva a la diferencia en los métodos utilizados. Los partidarios de la explicación aplican métodos cuantitativos y la observación con la intención de encontrar regularidades en la realidad internacional, mientras que los partidarios de la comprensión prefieren métodos cualitativos, pensamiento histórico y discursivo y, por consiguiente, la interpretación de lo que no es observable. Con esta línea de pensamiento basada en la comprensión está relacionado el constructivismo.

Simplificando, el debate entre el positivismo y el postpositivismo y entre el racionalismo y el pensamiento reflectivo "se superpone" sobre el debate mencionado antes entre la explicación y la comprensión. El positivismo y el racionalismo se aproximan a la explicación, mientras que el postpositivismo y el pensamiento reflectivo se acercan al enfoque sobre la comprensión en el proceso investigativo (Kurki, Wight 2013: 21-22). No obstante, una cuestión aparte es la utilidad de las mencionadas orientaciones teóricas que entran en el cuarto debate interparadigmático para la explicación los cambios cualitativos en el entorno internacional identificado con el orden westfaliano tardío. Resulta difícil dar una respuesta unívoca, aún más cuando en el problema principal de estos debates se convirtió el modo de realizar investigación y no el objeto de investigación. La cuestión es muy relevante, teniendo en cuenta que,
El cambio en la ontología y epistemología de la ciencia de relaciones internacionales

Marek Pietraś 
Dossier América Latina: desarrollo y balance de la ciencia política en particular desde la segunda mitad de los años 90 del siglo XX - también en Polonia (Pietraś 2002; Pietraś 2002a; Haliżak, Kuźniar, Symonides 2004) - un objeto importante de investigación en la ciencia de relaciones internacionales han sido los procesos de globalización, los cuales son el principal factor y, al mismo tiempo, el efecto de los cambios cualitativos en las relaciones internacionales y el surgimiento del orden internacional westfaliano tardío. Tomando en consideración la complejidad de estos cambios y su carácter cualitativo, parece que tanto el pensamiento explicativo como el pensamiento enfocado en la comprensión e interpretación muestran una utilidad limitada en el proceso de investigación del orden internacional westfaliano tardío por medio del enfoque sobre unos fenómenos, procesos y acciones parciales.

La reconstrucción del cuarto debate interparadigmático no significa que el tema de los procesos de globalización y el emergente orden westfaliano tardío no surgieron en absoluto (Pietraś 2005: 145-148). Los cambios cualitativos del entorno internacional empezaron a estimular a los investigadores de relaciones internacionales para indagar si el existente "aparato intelectual" de la disciplina, es decir, las escuelas de pensamiento y los métodos investigativos son suficientes para investigar estos cambios. El debate iniciado - ¿será el quinto? - empezó a desarrollarse entre, por un lado, los partidarios de la idea de que las existentes aproximaciones teóricas, creadas bajo el orden internacional westfaliano, son suficientes - James Mittelman los llamó "guardianes" (keepers) (Mittelman 2002: 3) - , y por el otro lado, los partidarios de crear un nuevo paradigma investigativo para examinar la nueva realidad internacional, a los cuales Kenneth Waltz llamó los "globalistas" (globalizers) (Waltz 1999: 693).

La corriente de los "guardianes" es diversificada. Incluye representantes de diferentes orientaciones investigativas: los neorealistas, los partidarios de la teoría de interdependencia y del institucionalismo neoliberal, así como también algunos teóricos de la teoría del sistema mundial. Lo que les une es la convicción que el "aparato intelectual" de su preferencia es capaz de analizar los cambios actuales, ya que consideran que muchos de estos cambios no constituyen un fenómeno nuevo (Pietraś 2005: 146-147).

Al grupo de los principales "globalistas", es decir, los partidarios de la tesis de que los procesos de globalización y el surgimiento del orden westfaliano tardío requieren un nuevo paradigma teórico en la ciencia de relaciones internacionales, pertenecen Ian Clark (Clark 1999), Jan Aart Scholte (Scholte 1999) y Philip Cerny (Cerny 1996, Cerny 2010), y en la ciencia de relaciones internacionales polaca Marek Pietraś (Pietraś 2005). Philip Cerny señaló que en el proceso de búsqueda de una alternativa a la escuela realista bajo unos cambios radicales en el entorno internacional, fue escogido un conjunto de ideas que hacen de los procesos de globalización el objeto de su análisis. Estas ideas son tratadas como una alternativa a la escuela realista o neorealista y, por consiguiente, como un elemento de búsqueda de una nueva orientación investigativa (Cerny 1996: 618). A su vez, Ian Clark mantiene que la investigación de los procesos de globalización no crea solo un marco de análisis de 
relaciones internacionales, pero también hace posible el surgimiento de una teoría de cambio (Clark 1999: 2). Esto significa el surgimiento de una nueva perspectiva investigativa en la ciencia de relaciones internacionales. Esta línea de pensamiento - además, en su versión radical - la confirma Jan Scholte, enfatizando que los procesos de globalización llevan al cambio del paradigma de esta ciencia, y aún más, un cambio irreversible (Scholte 1998: 9).

Una postura menos radical - pero mostrando cierto apoyo en cuanto al surgimiento de un nuevo paradigma de relaciones internacionales bajo los procesos de globalización y la emergencia del orden westfaliano tardío - la presentaron James Rosenau, Morten Ougaard y Richard Higgott. El primero, analizando el cambio de "parámetros" del entorno internacional bajo los procesos de globalización y, en particular, el desvanecimiento de la anterior clara separación entre lo intraestatal y lo internacional, subrayó que esto justifica la creación de un nuevo paradigma (Rosenau 1997: 80). A su vez, según Morten Ougaard y Richard Higgott, los procesos de globalización condicionan el surgimiento de un nuevo sistema político global, formado por los Estados junto con los sujetos transnacionales. En su opinión, por causa de estos cambios algunos conceptos referentes a las relaciones internacionales surgidos bajo el orden internacional westfaliano - como, por ejemplo, el concepto de la comunidad internacional o de los sistemas internacionales - son de utilidad limitada bajo los procesos de globalización (Ougaard, Higgott 2002: 10).

Las discusiones y opiniones presentadas muestran claramente que en la ciencia mundial de relaciones internacionales ya hace años, en el contexto de los cambios cualitativos en el entorno internacional, apareció la cuestión de la adecuación de las herramientas teóricas y de las escuelas de pensamiento formadas en la anterior realidad westfaliana para la explicación, interpretación y comprensión de la realidad westfaliana tardía. Hay investigadores quienes están convencidos de la necesidad de formar unas nuevas herramientas teóricas y nuevas escuelas de pensamiento, pero hay también los que están convencidos de que no hay justificación para una "revolución paradigmática" porque las existentes escuelas de pensamiento son suficientes. En la ciencia de relaciones internacionales en Polonia muy pocos investigadores perciben este problema.

La reconstrucción de los debates interparadigmáticos que han tenido lugar hasta ahora en la ciencia de relaciones internacionales justifica la pregunta sobre su futuro y, por consiguiente, la futura perspectiva de la teoría de relaciones internacionales. Un importante y valioso aporte a la respuesta a esta pregunta es la discusión iniciada en 2013 sobre el tema por la revista "European Journal of International Relations", a la cual se juntaron también otros investigadores. El tema principal de la discusión fueron los efectos del existente pluralismo teórico, la "proliferación" de las teorías, la formación de una “caja de herramientas teóricas" para el futuro desarrollo de la ciencia de relaciones internacionales. En la discusión aparecieron varias líneas de argumentación. Se llegó al acuerdo que actualmente ha disminuido la importancia de los grandes debates interparadigmáticos para el desarrollo de la disciplina.
El cambio en la ontología y epistemología de la ciencia de relaciones internacionales

Marek Pietraś 
Dossier América Latina: desarrollo y balance de la ciencia política
Sin embargo, el acuerdo sobre la disminución de importancia de los debates y su actual influencia en el desarrollo de la disciplina es la base de diferentes y muchas veces opuestas opiniones. Primero, David Lake cree que los debates como unos enfrentamientos intelectuales no han aportado mucho al desarrollo de la disciplina. Han atraído la atención del mundo académico, pero no han solucionado nada. En su opinión, no se han concentrado suficientemente en la explicación de las relaciones internacionales, más bien convirtiéndose en unas cuasi-religiones con una fuerte fe en su propio método (Lake 2013: 567). Esto supone una crítica del desarrollo de la disciplina que se ha efectuado hasta ahora alrededor de los debates. En este contexto, Andrew Bennett formula la propuesta de aceptar y desarrollar el eclecticismo teórico (Bennett 2013: 461), por lo tanto, el pluralismo de las teorías. Tal situación es considerada incluso como una prueba de madurez intelectual de la disciplina que excluye la hegemonía de una única teoría (Dunne, Hansen, Wight 2013: 406).

Segundo, John Mearsheimer y Stephen Walt perciben críticamente la falta de debates interparadigmáticas, pero advierten que también disminuye la actividad teórica del entorno de los investigadores de relaciones internacionales. Consideran que la falta de unos grandes debates teóricos es un movimiento lamentable hacia la posición privilegiada de la verificación de hipótesis en vez de la teorización (Mearsheimer, Walt 2013: 427).

Tercero, Ole Waever se muestra escéptico en cuanto a la desaparición de los grandes debates teóricos en el desarrollo de la disciplina a pesar de que muchos investigadores compartan esta opinión. Él cree que, en presente, con el pluralismo teórico, no hay un gran debate que organizaría el funcionamiento de la disciplina. Son llevadas a cabo varias debates en el marco de diferentes escuelas de pensamiento: 1) dentro del realismo - entre el ofensivo y el defensivo; 2) dentro del neoliberalismo - un debate sobre los diferentes modos de percibir instituciones y el concepto de la elección racional; 3) dentro del constructivismo - entre la corriente neoliberal y post-estructural; 4) dentro de diferentes corrientes reflectivistas, como el feminismo, la teoría crítica, el neomarxismo; 5) entre el racionalismo y el pensamiento reflectivista hay varios debates relacionados con unos problemas más detallados (Waever 2013: 317-321).

Cuarto, en una clara referencia a la metáfora de la "caja de herramientas", se formula una evaluación positiva del eclecticismo o el pluralismo teórico. Andrew Bennett señala que ninguna de las escuelas de pensamiento teórico contemporáneas no es capaz de captar la complejidad de las relaciones internacionales actuales. Aunque no lo expresa literalmente, da a entender que las teorías existentes, en la enredada realidad internacional, cumplen - de hecho - el papel de las teorías parciales. Ha subrayado, sin embargo, que el pluralismo de las teorías abre la posibilidad de escoger los instrumentos teóricos (Bennett 2013: 461). Además, se formula la opinión que junto con el creciente pluralismo teórico la ciencia de relaciones internacionales deja de ser una disciplina exclusivamente estadounidense, tal como lo fue en un período inicial de su desarrollo (Giorgio 2014: 813). 
Quinto, Chris Brown sugiere que no se debe desistir de construir una grande teoría general. Sin embargo, no cree que el constructivismo pueda cumplir este papel. Éste no es una teoría en el mismo sentido que el idealismo o realismo. Es más bien - según la opinión de Brown - un conjunto de disposiciones referentes a la percepción y aproximación en el proceso cognitivo a la realidad social, acentuando ideas, normas y valores, es decir, la esfera ideacional. Brown considera que el constructivismo sirve más bien para la identificación de los campos de investigación que para la explicación de la realidad internacional (Brown 2013: 490-491).

La revisión de la evolución de la esfera epistemológica de la ciencia de relaciones internacionales, de los debates interparadigmáticos, del estado actual del pluralismo teórico y la actual dispersión de opiniones sobre el rumbo de desarrollo de la disciplina muestran claramente que este campo de la ciencia está pasando por un período de cambio. Por causa de la creciente complejidad de la realidad internacional cada teoría existente se ha convertido en una teoría parcial. El pluralismo teórico existente justifica el uso de la metáfora de la "caja de herramientas", escogidas por el investigador según sus necesidades o preferencias.

Resumiendo, hay que recordar que el análisis llevado a cabo en este artículo ha confirmado que la ciencia de relaciones internacionales se encuentra en un proceso de transformación condicionada por el cambio - de características cualitativas - de la realidad internacional. La esfera teórica se está ajustando a la realidad internacional cada vez más compleja, transitando del anterior sistema westfaliano hacia el actual orden westfaliano tardío. Éste se caracteriza por la creciente complejidad, la fragmentación de realidad y la progresiva autonomización de los campos de investigación. A raíz de esto, se profundiza el pluralismo de teorías y métodos investigativos. Éstos se convierten en una especie de "caja de herramientas", de la que el investigador selecciona las herramientas para su trabajo, ajustándolas al objeto de su investigación en función de sus necesidades, preferencias o resultados esperados.

\section{Bibliografía}

Bennett A. (2013), The mother of all isms: Casual mechanism in International Relations theory, "European Journal of International Relations", no 19 (3), pp. 459-481.

Brown Ch. (2013), The poverty of Grand Theory, "European Journal of International Relations", no 19 (3), pp. 483-497.

Brühl T., Rittberger V. (2001), From international to global governance: Actors, collective decision-making, and United Nations in the world of twenty-first century, en: Global Governance and the United Nations System, V. Rittberger (ed.), United Nations University Press, New York.

Buzan B., Jones R. J. B. (eds.) (1981), Change and the Study of International Relations. The Evaded Dimension, Printer, London.
El cambio en la ontología y epistemología de la ciencia de relaciones internacionales

Marek Pietraś 
Dossier América Latina: desarrollo y balance de la ciencia política
Cerny P. G. (1996), Globalization and Other Stories: The Search for a New Paradigm for International Relations, "International Journal", no 51 (4), pp. 617-637.

Cerny P. G. (2010), Rethinking World Politics. A Theory of Transnational Neopluralism, Oxford University Press, New York, Oxford.

Clark I. (1999), Globalization and International Relations Theory, Oxford University Press, Oxford.

Czornik, K., Lakomy M., Stolarczyk M. (eds.) (2014), Dylematy polityki zagranicznej Polski na początku XXI wieku, Wydawnictwo Uniwersytetu Śląskiego, Katowice.

Dougherty J. E., Pfaltzgraff R. L. (1997), Contending theories of international relations: a comprehensive survey, Longman, New York.

Dudek A., (ed.) (2015), W kręgu nauki o stosunkach międzynarodowych. Księga dedykowana Profesor Teresie Łoś-Nowak, Wydawnictwo Rambler, Warszawa.

Dunne T., Hansen L., Wight C. (2013), The end of international relations theory? " European Journal of International Relations", no 19 (3), pp. 405-425.

Gałganek A. (1992), Zmiana $w$ globalnym systemie. Supercykle $i$ wojna hegemoniczna, Uniwersytet im. Adama Mickiewicza, Poznań.

Giddens A. (1999), Runaway world, Profile Books, London.

Gil G. (2015), Upadanie państwa w stosunkach międzynarodowych po zimnej wojnie, Wydawnictwo UMCS, Lublin.

Gilpin R. (1981), War and Change in World Politics, Cambridge University Press, Cambridge.

Giorgio D. (2014), Theories of International Relations: from an American Science towards a Pluralism of Thought, "Transition Studies Review", no 16 (4), pp. 813-828.

Grenier F. (2015), An eclectic fox: IR from restrictive discipline to hybrid and pluralist field, "International Relations", no 29 (2), pp. 250-254.

Grenier F., Turton H., Beaulieu-Brossard Ph. (2015), The struggle over the identity of IR: What is at stake in disciplinary debate within and beyond academia?, "International Relations", no 29 (2), pp. 242-244.

Guzzini S. (2013), The ends of International Relations theory: stages of reflexivity and modes of theorizing, "European Journal of International Relations", no 19 (3), pp. 521-541.

Haliżak E. (2015), Obszar badawczy nauki o stosunkach międzynarodowych, en: W kręgu nauki o stosunkach międzynarodowych. Księga dedykowana Profesor Teresie Łoś-Nowak, A. Dudek (ed.), Wydawnictwo Rambler, Warszawa.

Haliżak E., Kuźniar R., Symonides J. (eds.) (2004), Globalizacja a stosunki międzynarodowe, Oficyna Wydawnicza BRANTA, Warszawa.

Haliżak E. (2015), Przedmiot, teoria i metodologia nauki o stosunkach międzynarodowych, „Stosunki Międzynarodowe”, no 51 (1), pp. 12-34.

Haliżak E., Pietraś M. (eds.) (2013), Poziomy analizy stosunków międzynarodowych, PTSM/ Rambler, Warszawa.

Held D. (2004), A Globalizing World? Culture, Economics and Politics, Routledge, London.

Hollis M., Smith S. (1990), Explaining and understanding international relations, Clarendon, Oxford.

Hudzik J. (2011), Teoria polityki $w$ komentarzach filozoficznych $i$ metodologicznych, en: Czym jest teoria w politologii?, Z. Blok (ed.), Elipsa, Warszawa. 
Kaplan M. (1964), System and Process in International Politics, Willey, New York.

Kellner D. (1998), Globalization and the Postmodern Turn, en: Globalization and Europe, R. Axtmann (ed.), Cassells, London.

Kempny M. (2000), Czy globalizacja kulturowa współdecyduje o dynamice społeczeństw postkomunistycznych, „Kultura i Społeczeństwo”, no XLIV (1), pp. 5-23.

Krauz-Mozer B. (2011), Teoretyzowanie w politologii u progu XXI wieku, en: Czym jest teoria w politologii?, Z. Blok (ed.), Elipsa, Warszawa.

Kukułka J. (ed.) (1991), Internacjonalizacja życia narodów i państw, Warszawa.

Kurki M., Wight C. (2013), International relations and social science, en: International relations theories. Discipline and diversity, T. Dunne, M. Kurki, S. Smith (eds.), Oxford University Press, Oxford.

Kuźniar R. (2006), Stosunki międzynarodowe - istota, uwarunkowania, badanie, en: Stosunki międzynarodowe - geneza, struktura, dynamika, E. Haliżak, R. Kuźniar (eds.), Wydawnictwa UW, Warszawa.

Kuźniar R. (1988), Współzależność jako prawidłowość stosunków międzynarodowych, „Sprawy Międzynarodowe”, no 41 (4), pp. 110-125.

Kuźniar R. (ed.) (2005), Porządek międzynarodowy u progu XXI wieku, Wydawnictwa Uniwersytetu Warszawskiego, Warszawa.

Lake D. (2013), Theory is dead, long live theory: the end of the Great Debates and the rise of eclecticism in International Relations, "European Journal of International Relations", no 19 (3), pp. 567-587.

Łoś-Nowak T. (2014), Przestrzeń międzynarodowa versus środowisko międzynarodowe: nowe zjawiska, nowe wyzwania dla polityki zagranicznej RP, en: Dylematy polityki zagranicznej Polski na poczatku XXI wieku, K. Czornik, M. Lakomy, M. Stolarczyk (eds.), Wydawnictwo Uniwersytetu Śląskiego, Katowice.

Łoś-Nowak T. (2006), Stosunki międzynarodowe. Teorie - systemy - uczestnicy, Wydawnictwo Uniwersytetu Wrocławskiego, Wrocław.

Łoś-Nowak T. (2009), Wyjaśnić czy interpretować? Dylematy i wyzwania czwartej debaty interparadygmatycznej, „Stosunki Międzynarodowe”, no 39 (1-2), pp. 29-48.

Łoś-Nowak, T. (ed.) (2011), Polityka zagraniczna. Aktorzy, potencjały, strategie, Poltext, Warszawa.

Mania A., Kłosowicz R. (eds.) (2012), Problem upadkupaństwwstosunkachmiędzynarodowych, Wydawnictwo Uniwersytetu Jagiellońskiego, Kraków.

Marzęda-Młynarska K. (2014), Globalne zarządzanie bezpieczeństwem żywnościowym na przełomie XX i XXI wieku, Wydawnictwo UMCS, Lublin.

Mearsheimer J. J., Walt S. M. (2013), Leaving theory behind: Why simplistic hypothesis testing is bad for International Relations, "European Journal of International Relations", no 19 (3), pp. $427-457$.

Meyers R. (1991), Grundbegriffe, Strukturen und theoretische Perspektiven der Internationalen Beziehungen, en: Grundwissen Politik, Bonn.

Mittelman J. (2002), Globalization: an ascendant Paradigm, "International Studies Perspectives", no 3 (1), pp. 1-14.

Neufeld M. (1993), Interpretation and the „science” of international relations, "Review of International Studies”, no 19 (1), pp. 39-61.
El cambio en la ontología y epistemología de la ciencia de relaciones internacionales

Marek Pietraś 
Dossier

América Latina: desarrollo y balance de la ciencia política
Ougaard M., Higgott R. (2002), Introduction: Beyond System and Society - Towards Global Polity?, en: Towards a Global Polity, M. Ougaard, R. Higgott (eds.), Routledge, New York.

Palan R. (2007), Transnational theories of order and change: heterodoxy in international relations scholarship, "Review of International Studies", no 33 (S1), pp. 47-69.

Panas E. (2013), Soft power transnarodowych organizacji społeczeństwa obywatelskiego, Lublin (tesis doctoral no publicada).

Pastusiak L. (1986), Współczesne paradygmaty teoretyczne stosunków międzynarodowych, „Studia Nauk Politycznych”, no 6.

Pietraś M. (ed.) (2002), The Faces of Globalisation, Maria Curie-Skłodowska University Press, Lublin.

Pietraś M. (2002a), Istota i zakres procesów globalizacji, „Sprawy Międzynarodowe”, no 54 (2), pp. 5-34.

Pietraś M. (2002b), Globalisation as a process of changing the international community, en: The Faces of Globalisation, M. Pietraś (ed.), Maria Curie-Skłodowska University Press, Lublin.

Pietraś M. (2005), Paradygmat globalizacji in statu nascendi, en: Porzadek międzynarodowy u progu XXI wieku, R. Kuźniar (ed.), Wydawnictwa Uniwersytetu Warszawskiego, Warszawa.

Pietraś M. (ed.) (2007), Międzynarodowe stosunki polityczne, Wydawnictwo UMCS, Lublin.

Pietraś M. (2007a), Istota i ewolucja międzynarodowych stosunków politycznych, en: Międzynarodowe stosunki polityczne, M. Pietraś (ed.), Wydawnictwo UMCS, Lublin.

Pietraś M., Piórko K. (2007), Podmioty transnarodowe, en: Międzynarodowe stosunki polityczne, M. Pietraś (ed.), Wydawnictwo UMCS, Lublin.

Pietraś M. (2007b), Late Westphalian International Order, "Polish Political Science Yearbook", no 36, pp. 134-157.

Pietraś M. (2008), Hybrydowość późnowestfalskiego ładu międzynarodowego, en: Poźnowestfalski ład międzynarodowy, M. Pietraś, K. Marzęda (eds.), Wydawnictwo UMCS, Lublin.

Pietraś M., Marzęda K. (eds.), (2008) Poźnowestfalski ład międzynarodowy, Wydawnictwo UMCS, Lublin.

Pietraś M. (2009), Dynamika globalnego środowiska międzynarodowego. Analiza uwarunkowań systemowych, en: Demokratyczna Polska w globalizujacym się świecie, K. A. Wojtaszczyk, A. Mirska (eds.), Wydawnictwa Akademickie i Profesjonalne, Warszawa.

Pietraś M. (2013), Przestrzeń transnarodowa jako poziom analizy w nauce o stosunkach międzynarodowych, en: Poziomy analizy stosunków międzynarodowych, E. Haliżak, M. Pietraś (eds.), PTSM/Rambler, Warszawa.

Pietraś M. (2014), Teoria i praktyka reżimów międzynarodowych, en: Stosunki międzynarodowe - wokół zagadnień teoretycznych, K. Kącka (ed.), Wydawnictwo Naukowe UMK, Toruń.

Pietraś M. (2015), Hiperpoliarchiczność transnarodowej przestrzeni społecznej, en: W kręgu nauki o stosunkach międzynarodowych. Księga dedykowana Profesor Teresie Łoś-Nowak, A. Dudek (ed.), Wydawnictwo Rambler, Warszawa.

Pietraś M. (2015a), Przestrzeń badawcza nauki o stosunkach międzynarodowych, „Politeja”, no 36 (4), pp. 65-97. 
Pugacewicz T. (2014), Mechanizm kształtowania polityki Stanów Zjednoczonych Ameryki wobec regionu Morza Kaspijskiego po 1991, Kraków, (tesis doctoral no publicada).

Rengger N., Thivkell-White B. (2007), Still critical after all these years? The past, present and future of critical theory in international relations, "Review of International Studies", no 33 (S1), pp. 3-24.

Richmond O. (2002), Maintaining Order, Making Peace, Palgrave, New York.

Rosecrance R. N. (1999), The rise of the virtual state: wealth and power in the coming century, Basic, New York.

Rosenau J. N. (1988), Patterned Chaos in Global Life: Structure and Process in the Two Worlds of World Politics, "International Political Science Review", no 9 (4), pp. 327-364.

Rosenau J. N. (1997), Along the Domestic Foreign Frontier: Exploring Governance in a Turbulent World, Cambridge University Press, Cambridge.

Rosenau J. N. (1989), Global changes and Theoretical Challenges: Towards a Postinternational Politics for the 1990s., en: Global Changes and Theoretical Challenges. Approaches to World Politics for the 1990s., E. O. Czempiel, J. N. Rosenau (eds.), Lexington Books, Lexington.

Rosenau J. N. (1996), The Dynamics of Globalization: Toward an Operational Formulation, "Security Dialogue", no 22 (1), pp. 247-262.

Rosenau J. N. (2006), The Study of World Politics. Theoretical and Methodological Challenges, vol. 1, Routledge, New York.

Rosenau J. N. (1990), Turbulence. World Politics. A Theory of Change and Continuity, Harvester Wheatsheaf, London.

Schachter M. G. (1999), Civil Society and Globalization: The Investigation of Contested Concepts, en: The Revival of Civil Society: Global and Comparative Perspectives, M. G. Schachter (ed.), Macmillan, Basingstoke.

Scholte J. A. (1996), Beyond the Buzzword: Towards a Critical Theory of Globalization, en: Globalization: Theory and Practice, E. Kofman, G. Youngs (eds.), Printer, London.

Scholte J. A. (1999), Globalization: Prospects for a Paradigm Shift, en: Politics in Globalized World, M. Shaw (ed.), Routledge, London.

Scholte J. A. (1997), The Globalization of World Politics, en: The Globalization of World Politics. An Introduction to International Relations, J. Baylis, S. Smith (eds.), Oxford University Press, Oxford.

Silvester Ch. (2013), Experiencing the end and afterlives of International Relations theory, "European Journal of International Relations", no 19 (3), pp. 609-626.

Smith S. (2013), Introduction: Diversity and disciplinarity in international relations theory, en: International relations theories. Discipline and diversity, T. Dunne, M. Kurki, S. Smith (eds.), Oxford University Press, $3^{\text {rd }}$ ed., Oxford.

Surmacz B. (2015), Ewolucja współczesnej dyplomacji. Aktorzy, struktury, funkcje, Wydawnictwo UMCS, Lublin.

Turton L. H. (2015), The importance of re-affirming IR's disciplinary status, "International Relations", no 29 (2), pp. 244-250.

Valaskakis K. (2000), Westphalia II: The Real Millennium Challenge, <http://www.paricenter. com/library/ papers/valaskakis01.pdf.

Vincent R. J. (1983), Change and international relations, "Review of International Studies", no 9 (1), pp. 63-70.
El cambio en la ontología y epistemología de la ciencia de relaciones internacionales

Marek Pietraś 
Dossier América Latina: desarrollo y balance de la ciencia política
Waever O. (2013), Still a discipline after all these debates?, en: International relations theories. Discipline and diversity, T. Dune, M. Kurki, S. Smith (eds.), Oxford University Press, Oxford.

Waever O. (1996), The rise and fall of the interparadigm debate, en: International theory: positivism and beyond, S. Smith, K. Booth, M. Zalewski (eds.), Cambridge University Press, Cambridge.

Wallace W. (1996), Truth and power: monks and technocrats: theory and practice in international relations theory, "Review of International Studies", no 22 (3), pp. 301-321.

Walt S. (1998), International Relations: One World, Many Theories, "Foreign Policy", no 110, pp. 29-46.

Waltz K. N. (1999), Globalization and Governance, "Political Science and Politics", no 32 (4), pp. 693-700.

Waltz K. (1979), Theory of International Politics, McGraw-Hill, Boston.

Waltz K. (1981), The Spread of Nuclear Weapons: More May Better, Adelphi Papers 171, International Institute for Strategic Studies, London.

Wendt A. (2008), Społeczna teoria stosunków międzynarodowych, Wydawnictwo Naukowe Scholar, Warszawa.

Zachara M. (2012), Global governance. Lad międzynarodowy po zakończeniu stulecia Ameryki, Wydawnictwo Uniwersytetu Jagiellońskiego, Kraków. 